\title{
REVIEW
}

\section{NADPH oxidase(s): new source(s) of reactive oxygen species in the vascular system?}

\author{
L Van Heerebeek, C Meischl, W Stooker, C J L M Meijer, H W M Niessen, D Roos
}

J Clin Pathol 2002;55:561-568

Reactive oxygen species play an important role in a variety of (patho)physiological vascular processes. Recent publications have produced evidence of a role for putative non-phagocyte NADP oxidase(s) in the vascular production of reactive oxygen species. In the present review, we discuss the detection of the different components of NADP oxidase(s) in the vascular system, together with the putative role of reactive oxygen species produced by vascular NADPH oxidase(s), in both in vitro and in vivo studies.

See end of article for authors' affiliations

...........................

Correspondence to: Dr H W M Niessen Department of Pathology, Free University Medical Centre, PO Box 7057, 1007 MB Amsterdam, The Netherlands; jwm.niessen@vumc.nl

Accepted for publication 6 March 2002
T he NADPH oxidase of phagocytic leucocytes is the source of the reactive oxygen species (ROS) that these cells need to kill invading pathogens. In recent years, numerous reports have produced evidence of a role for putative non-phagocyte NADPH oxidase(s) in the vascular production of ROS, because several of the components of the phagocyte NADPH oxidase have been detected in vascular tissue of several animal species, including humans. However, these studies suggest distinct differences in amino acid sequence (and antibody reactivity) between the central subunits of the phagocyte and nonphagocyte NADPH oxidase(s). ROS produced by these putative non-phagocyte NADPH oxidase(s) are involved in various (patho)physiological responses of vascular cells, such as mitosis, apoptosis, migration, hypertrophy, and modification of the extracellular matrix. Accordingly, ROS have been implicated in several major intracellular signalling pathways leading to changes in gene transcription and protein synthesis. Therefore, it is not surprising that ROS are thought to play an important role in disease processes, such as atherosclerosis and tumour progression, among others. In this review, we will discuss the evidence for a role of NADPH oxidase(s) in various (patho) physiological processes of the vascular system.

"Reactive oxygen species have been implicated in several major intracellular signalling pathways leading to changes in gene transcription and protein synthesis"

\section{THE NADPH OXIDASE OF PHAGOCYTIC} LEUCOCYTES

NADPH oxidase has been studied extensively in phagocytes (neutrophilic and eosinophilic granulocytes, monocytes, and macrophages). Exposure of these cells to any of a large number of stimuli activates a respiratory burst, caused by an activation of the plasma membrane bound NADPH oxi- dase. Upon activation, the NADPH oxidase catalyses the one electron reduction of oxygen, using NADPH as the electron donor ${ }^{1}$ :

$$
\mathrm{NADPH}+2 \mathrm{O}_{2} \rightarrow \mathrm{NADP}^{+}+2 \mathrm{O}_{2}^{-}+\mathrm{H}^{+}
$$

The superoxide anion radicals $\left(\mathrm{O}_{2}^{-}\right)$generated in this way play a prominent role in oxygen dependent bacterial killing. $\mathrm{O}_{2}^{-}$can be dismutated to hydrogen peroxide $\left(\mathrm{H}_{2} \mathrm{O}_{2}\right)$, either spontaneously or by the antioxidant enzyme superoxide dismutase, and $\mathrm{H}_{2} \mathrm{O}_{2}$ may subsequently be converted into a variety of active oxygen species, such as singlet oxygen and hydroxyl radicals. ${ }^{2}$ The NADPH oxidase of phagocytes is composed of at least five protein subunits. Gp9lphox and p22phox are transmembrane proteins that need each other to form a stable flavocytochrome $b_{558}{ }^{3}$ Three other components, p47phox, p67phox, and p40phox are localised in the cytosol ${ }^{4}$ of resting cells and, upon stimulation of the cells by various agents, these components translocate to the flavocytochrome to form the active enzymatic NADPH oxidase complex ${ }^{5}$ (fig 1). In addition to these subunits, the regulatory low molecular weight GTPases, Racl (in macrophages), ${ }^{6}$ Rac2 (in neutrophils), ${ }^{7}$ and RaplA, ${ }^{8}$ participate in the assembly of the active complex.

\section{NON-PHAGOCYTE, VASCULAR NADPH OXIDASE(S)}

NADPH oxidase components have also been detected in non-phagocytic cells. However, the catalytic subunit of the non-phagocyte NADPH oxidase(s) appears to be genetically and structurally distinct from its phagocyte counterpart gp9lphox. This has been demonstrated-for example, in patients with the $\mathrm{X}$ linked form of the immunodeficiency syndrome chronic granulomatous disease (CGD), ${ }^{9}$ which is characterised by the lack of or strongly reduced NADPH oxidase activity in phagocytes caused by an absent or defective gp9lphox protein. ${ }^{10}{ }^{11}$ However, fibroblasts of such patients contain a spectroscopically normal cytochrome $\mathrm{b}_{558}$ content compared with control fibroblasts and show a comparable $\mathrm{O}_{2}^{-}$production.'

Abbreviations: Ang, angiotensin; $C A D$, coronary artery disease; CGD, chronic granulomatous disease; DPI, diphenylene iodonium; $E R$, endoplasmic reticulum; HUVEC, human umbilical vein endothelial cell; LPS, lipopolysaccharide; PMA, phorbol-12-myristate-13-acetate; ROS, reactive oxygen species; RT-PCR, reverse transcriptase polymerase chain reaction; SMC, smooth muscle cell; TNF- $\alpha$, tumour necrosis factor $\alpha$; VSMC vascular smooth muscle cell 


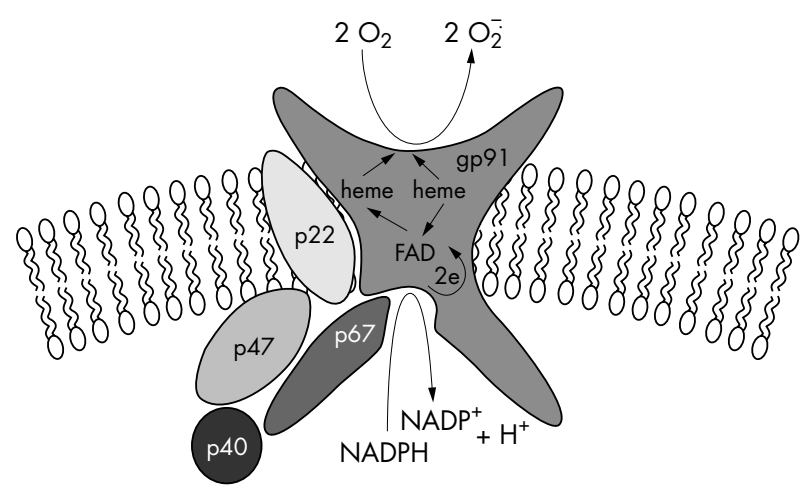

Figure 1 Composition of the NADPH oxidase in phagocytic cells.

In recent years, the expression of components of the NADPH oxidase in the vascular system has been studied by various methods (tables 1 and 2 ).

\section{DETECTION OF P22PHOX IN BLOOD VESSELS Endothelial cells}

Animal

p22phox mRNA and protein have been detected in rat non-atherosclerotic coronary microvascular endothelial cells with the reverse transcriptase polymerase chain reaction (RTPCR), ${ }^{12}{ }^{13}$ CDNA sequence analysis, ${ }^{12}$ northern blotting, ${ }^{12}$ and western blot analysis. ${ }^{12}$

In these cells, p22phox was also detected with confocal immunofluorescence microscopy in perinuclear regions, in the vicinity of the endoplasmic reticulum (ER) and towards the cell membrane. ${ }^{12}$ Non-atherosclerotic porcine pulmonary artery endothelial cells have been shown to express p22phox by immunohistochemistry and RT-PCR. ${ }^{14}$

\section{Human}

In humans, p22phox expression has been demonstrated in atherosclerotic coronary artery endothelial cells by means of immunohistochemistry and western blotting. ${ }^{26}$ p22phox expression was also detected by northern blotting, ${ }^{23} \mathrm{RT}^{2} \mathrm{PCR},{ }^{23-25}$ cDNA library screening, ${ }^{24}$ and western blotting in the membrane fraction of the endothelium ${ }^{24}$ in humans. The same cells have also has been reported to express membrane associated flavocytochrome $\mathrm{b}_{558}{ }^{25}$ In contrast, heme spectroscopy failed to detect the flavocytochrome $b_{558}$ in these cells. ${ }^{23}$
Vascular smooth muscle cells (VSMCs)

Animal

p22phox expression has been demonstrated in nonatherosclerotic rat thoracic aorta VSMCs by RT-PCR, ${ }^{15}$ northern blot analysis, ${ }^{15-17}$ and sequencing of p22phox cDNA. ${ }^{15}$ Furthermore, p22phox expression was suggested by downregulation after transfection with antisense p22phox oligonucleotides in human umbilical vein endothelial cells (HUVECs). ${ }^{16}$ In addition, a cDNA for flavocytochrome $b_{558}$ (composed of p22phox and gp9lphox) has been isolated from rat VSMCs; this molecule shows a substantial resemblance to both the mouse and the human amino acid sequence and nucleotide sequence, respectively. ${ }^{15}$ In contrast, in another study, the presence of p22phox could not be demonstrated in the non-atherosclerotic rat thoracic aortic medial layer by immunohistochemical staining, which exclusively showed adventitial expression of p22 phox. $^{18}$

\section{Human}

In humans, p22phox expression has been detected in atherosclerotic coronary artery VSMCs by means of immunohistochemistry, western blot analysis, ${ }^{26}$ and RT-PCR, and with northern blotting in non-atherosclerotic aortic smooth muscle cells (SMCs). ${ }^{27}$ In addition, the expression of p22phox was suggested from antisense p22phox transfection experiments in VSMCs ${ }^{27}$ and in mesenteric artery SMCs. ${ }^{16}$ Western blot analysis pointed to the expression of p22phox at the plasma membrane of non-atherosclerotic aortic SMCs. ${ }^{24}$

\section{Adventitial fibroblasts \\ Animal}

Adventitial localisation of fibroblastic p22phox expression seems to predominate, as demonstrated by immunohistochemical staining in non-atherosclerotic rat thoracic aorta adventitial fibroblasts ${ }^{18}$ and rabbit aorta adventitial fibroblasts. ${ }^{19}$

\section{Human}

Immunohistochemical staining and western blotting also showed primarily adventitial expression of p22phox in human coronary artery fibroblasts, which increased in atherosclerotic coronary artery lesions, although at the same time extending throughout the entire vessel wall. ${ }^{26}$

\section{DETECTION OF GP91PHOX IN BLOOD VESSELS Endothelial cells}

Animal

RT-PCR and western blot analysis have demonstrated the expression of gp9lphox in rat non-atherosclerotic coronary

Table 1 NADPH subunits detected by various molecular biological techniques in animal experiments

\begin{tabular}{|c|c|c|c|c|c|c|c|c|}
\hline Subunit & Cell type & $\begin{array}{l}\text { Western } \\
\text { blotting }\end{array}$ & $\begin{array}{l}\text { Northern } \\
\text { blotting }\end{array}$ & RT-PCR & $\mathrm{ICH}$ & $\begin{array}{l}\text { DNA } \\
\text { sequencing }\end{array}$ & Anti-sense & Refs \\
\hline \multirow[t]{4}{*}{ p22phox } & ec & $r+$ & $r+$ & $r, p+$ & $r, p+$ & $r+$ & & $12-14$ \\
\hline & vsmc & & $r+$ & $r+$ & $r+$ & $r+$ & $r+$ & $15-18$ \\
\hline & $f b$ & & & & $r-$ & & & 18 \\
\hline & & & & & $r, r b+$ & & & 18,19 \\
\hline \multirow{3}{*}{ gp91 phox } & ec & $r+$ & $r-$ & $r, p+$ & $r, p+$ & $r+$ & & $\begin{array}{l}12-14 \\
12\end{array}$ \\
\hline & vsmc & $c+$ & & & & & & \\
\hline & $\mathrm{fb}$ & & & & $r, r b+$ & & & 18,19 \\
\hline \multirow[t]{2}{*}{ p47phox } & $\begin{array}{l}\text { ec } \\
\text { ysme }\end{array}$ & $b+$ & & & $p, b+$ & & & 14,21 \\
\hline & $\mathrm{fb}$ & & & & $r, r b+$ & & & 18,19 \\
\hline \multirow[t]{2}{*}{ p67phox } & ec & & & & $p+$ & & & 14 \\
\hline & $\begin{array}{l}\text { vsmc } \\
\mathrm{fb}\end{array}$ & & $\mathrm{rb}+$ & $\mathrm{rb}+$ & $r, r b+$ & & & $18,19,22$ \\
\hline
\end{tabular}

Cell type: ec, endothelial cell; $\mathrm{fb}$, fibroblast; vsmc, vascular smooth muscle cell. Animal species: $b$, bovine; $c$, calf; $m$, mouse; p, porcine; r, rat; rb, rabbit; + present; - absent.

ICH, immunohistochemistry; RT-PCR, reverse transcription polymerase chain reaction. 


\begin{tabular}{|c|c|c|c|c|c|c|c|c|c|}
\hline Subunit & Cell type & $\begin{array}{l}\text { Western } \\
\text { blotting }\end{array}$ & $\begin{array}{l}\text { Northern } \\
\text { blotting }\end{array}$ & RT- PCR & $\mathrm{ICH}$ & $\begin{array}{l}\text { DNA } \\
\text { sequencing }\end{array}$ & Spectroscopy & Anti-sense & Refs \\
\hline \multirow[t]{5}{*}{ p22phox } & huvec & + & + & + & & + & & & $23-25$ \\
\hline & & & & & & & - & & 23 \\
\hline & $\mathrm{ca} \mathrm{ec}$ & + & & & + & & & & 26 \\
\hline & vsmc & + & + & + & + & & & + & $16,26,27$ \\
\hline & $\mathrm{fb}$ & + & & & + & & & & 23,28 \\
\hline \multirow[t]{3}{*}{ gp91 phox } & huvec & + & & + & & & & & $23-25$ \\
\hline & & & & & & & - & & 23 \\
\hline & $\begin{array}{l}\text { vsmc } \\
\mathrm{fb}\end{array}$ & - & & - & & & & & 24 \\
\hline \multirow[t]{2}{*}{ p47phox } & huvec & + & & + & + & & & & 23,25 \\
\hline & $\begin{array}{l}\text { vsmc } \\
\mathrm{fb}\end{array}$ & + & & + & & & & & 29 \\
\hline \multirow[t]{2}{*}{ p67phox } & huvec & + & & + & + & & & & 23,25 \\
\hline & $\begin{array}{l}\text { vsmc } \\
\mathrm{fb}\end{array}$ & - & & - & & & & & 29 \\
\hline
\end{tabular}

Cell type: ca ec, coronary artery endothelial cell; fb, fibroblast; huvec, human umbilical vein endothelial cell; vsmc, vascular smooth muscle cell. $\mathrm{ICH}$, immunohistochemistry; RT-PCR, reverse transcription polymerase chain reaction.

microvascular endothelial cells. ${ }^{13}$ Another study reported the expression of gp9lphox in non-atherosclerotic rat coronary endothelial cells by RT-PCR and consecutive cDNA sequence analysis, but failed to do so by northern blot analysis. ${ }^{12}$ Interestingly, using confocal immunofluorescence microscopy the same study demonstrated gp9lphox expression extending from perinuclear areas and in the vicinity of the ER towards the cell membrane. ${ }^{12}$ In non-atherosclerotic porcine pulmonary artery endothelial cells gp9lphox expression was detected by immunohistochemistry and RT-PCR. ${ }^{14}$

\section{Human}

RT-PCR ${ }^{23-25}$ and western blotting ${ }^{25}$ have demonstrated gp9lphox mRNA and protein expression in HUVEC lines. ${ }^{23-25}$ In contrast, the gp9lphox component of the flavocytochrome $\mathrm{b}_{558}$ could not be demonstrated by heme spectroscopy in HUVECs. ${ }^{23}$

\section{Vascular smooth muscle cells \\ Animal \\ Western blot analysis indicated gp9lphox expression in non-atherosclerotic calf pulmonary artery VSMCs. ${ }^{20}$ \\ Human \\ Görlach et al were unable to detect gp9lphox mRNA or protein expression by means of RT-PCR or western blotting in human non-atherosclerotic aortic SMCs. ${ }^{24}$ \\ Adventitial fibroblasts: animal \\ Adventitial fibroblasts in the non-atherosclerotic rat thoracic aorta $^{18}$ and rabbit aorta ${ }^{19}$ were shown to express gp9lphox as detected by immunohistochemical staining. \\ DETECTION OF P47PHOX IN BLOOD VESSELS Endothelial cells \\ Animal}

Immunohistochemistry ${ }^{14}{ }^{21}$ and western blotting ${ }^{21}$ have demonstrated p47phox expression in non-atherosclerotic porcine pulmonary artery endothelial cells ${ }^{14}$ and bovine pulmonary artery endothelial cells. ${ }^{21}$

\section{Human}

In HUVECs, p47phox mRNA expression was demonstrated by means of RT-PCR ${ }^{23}$ and western blotting, ${ }^{25}$ and p47phox was localised in the cytosol of these cells by means of immunohistochemistry. ${ }^{23}$
Vascular smooth muscle cells: human

RT-PCR and western blotting demonstrated p47phox mRNA and protein expression in non-atherosclerotic human aortic SMCs. ${ }^{29}$

\section{Adventitial fibroblasts: animal}

Immunohistochemical staining showed p47phox expression in non-atherosclerotic aortic adventitial fibroblasts of rats ${ }^{18}$ and rabbits. ${ }^{19}$

\section{DETECTION OF P67PHOX IN BLOOD VESSELS Endothelial cells \\ Animal}

Porcine non-atherosclerotic pulmonary artery endothelial cells were shown by immunohistochemistry to express p67phox. ${ }^{14}$

\section{Human}

Immunohistochemistry, ${ }^{23}$ RT-PCR, ${ }^{23}{ }^{25}$ and western blotting ${ }^{25}$ have demonstrated p67phox mRNA and protein expression in HUVECs. ${ }^{23} 25$

\section{Vascular smooth muscle cells: human}

Neither RT-PCR nor western blot analysis could detect p67phox protein expression in non-atherosclerotic human aortic smooth muscle cells. ${ }^{29}$

\section{Adventitial fibroblasts: Animal}

p67phox expression was detected by RT-PCR, ${ }^{22}$ northern blot analysis, ${ }^{22}$ and immunohistochemical staining in nonatherosclerotic $\operatorname{rat}^{1819}$ and rabbit aortic adventitial fibroblasts. ${ }^{22}$

In summary, most, but not all of the phagocyte NADPH oxidase components have been found in the various cell types composing the atherosclerotic and non-atherosclerotic vasculature. However, when interpreting these sometimes conflicting reports, the lack of appropriate negative controlsmaterial from patients with CGD or relevant knockout micehas to be noted in most of these studies. Particularly for the central subunit of the NADPH oxidase, gp9lphox, the possibility of crossreactivity of oligonucleotides or antibodies with one or more of the gp9lphox homologues (see below) has to be taken into account. So far, to our knowledge, no extraphagocyte deficiencies of NADPH oxidase components in patients with CGD have been described. ${ }^{24}$

\section{GP91PHOX HOMOLOGUES}

Over the past two years several novel gp9lphox homologues have been described, which will be briefly mentioned in the 
following section, with the nomenclature recently accepted by the HUGO Human Gene Nomenclature Committee (http:// www.gene.ucl.ac.uk/nomenclature/). The names in parentheses indicate various names used in the original descriptions.

\section{Nox2 (gp91 phox)}

The prototype (and for a long time the only) member of the new family of NADPH oxidases, gp9lphox, is a 91 kDa glycosylated protein with six hydrophobic, probably membrane spanning, segments in its $\mathrm{N}$-terminal half. Four histidine residues in this transmembrane cluster have been shown to participate in the ligation of two hemes. The cytosolic C-terminal half of the protein contains FAD and NADPH binding sites homologous to those found in some other flavoproteins; it also encompasses as yet poorly defined regions of interaction with the cytosolic oxidase components p47phox and p67phox. ${ }^{3}$

All the gp9lphox homologues described so far have conserved the overall structure of six transmembrane segments with heme coordinating histidines, followed by a cytosolic part that contains highly conserved binding sites for FAD and NADPH. Although the homologues share other regions of high homology, nothing can yet be said about possible interactions with the other subunits of the phagocytic NADPH oxidase.

\section{Nox1 (Mox-1, NOH-1)}

Mox-1 mRNA is expressed in colon, prostate, uterus, and vascular smooth muscle cells, but was not found in peripheral blood leucocytes. ${ }^{30}$ Interestingly, and in contrast to neutrophils, ROS produced by mox-1 seem to be generated intracellularly. Furthermore, overexpression of mox-1 resulted in increased cell growth, suggesting a possible role for mox-1 in growth regulation. ${ }^{30}$

\section{Nox3 (gp91-3)}

To date, nothing is known about this homologue except for a seemingly exclusive expression in fetal kidney tissue (and the HepG2 cell line), as determined by RT-PCR. ${ }^{31}$

\section{Nox4 (renox, Kox-1)}

Another gp9lphox homologue, Nox4, has been detected by in situ RNA hybridisation and by immunohistochemistry in the renal cortex, predominantly in proximal convoluted tubule epithelial cells, which is also the putative site of erythropoietin production. ${ }^{32}$ In addition, human embryonic kidney 293 cells appear to express Nox4 mRNA and protein as detected by RT-PCR and western blot analysis. ${ }^{33}$ Based on the expression pattern it has been suggested that renox participates in the oxygen sensing mechanism that regulates the production of erythropoietin. Transfection of renox cDNA into NIH 3T3 fibroblasts resulted in enhanced superoxide production compared with control fibroblasts. However, in contrast to the results seen with mox-1, these modified fibroblasts displayed substantially diminished cell growth. ${ }^{32} 33$

\section{Nox5}

Recently, the sequence of this homologue, reportedly expressed in renal epithelial cells, was deposited in GenBank (AK026011 and AF317889).

\section{Duox 1 and Duox2 (ThOX1 and ThOX2/p138 ${ }^{\text {Tox }}$ )}

Discovered by low stringency screening of thyroid cell cDNA libraries with a gp9lphox probe, ThOX1 and ThOX2 represent a separate subgroup in the family of gp9lphox homologues. ${ }^{34}$ Also called Duox 1 and Duox2 (for dual oxidases 1 and 2), they are characterised by an $\mathrm{N}$-terminal extension that contains a peroxidase homology domain, a conserved calcium binding motif, and an additional transmembrane segment. Expressed specifically in the thyroid gland, at the apical membrane of thyrocytes, the two oxidases are thought to be involved in the biosynthesis of thyroid hormone. ${ }^{34}$
In summary, the discovery of the above described nonphagocyte gp9lphox homologues represents the first confirmation of earlier research in different tissues that had postulated a role for such homologues in a variety of signalling pathways. Future developments, which may include the description of additional, tissue specific oxidases, will need to elucidate the regulation and the role of these enzymes that are thought to be central to a new, redox dependent signalling mechanism.

\section{ROLES OF ROS PRODUCED BY VASCULAR NADPH OXIDASE(S)}

The search outlined above for NADPH oxidase components in vascular tissues and for gp9lphox homologues has been stimulated by the realisation that ROS are involved in several important processes of vascular functioning. Atherosclerosis, in particular, seems to be at the crossroads of a variety of ROS mediated pathophysiological signalling routes, such as SMC proliferation, the induction of early growth response gene transcription, the induction of adhesion molecule expression, and the consecutive activation of inflammatory response mechanisms. Although much of the evidence presented so far has been circumstantial, the discovery of key players, such as the novel gp9lphox homologues, should accelerate the elucidation of these essential signalling networks. In the following section we will present an overview of the current knowledge concerning the role of NADPH oxidase generated ROS in the (patho)physiology of the vasculature. Several components of the NADPH oxidase(s) appear to be associated with important determinants of vascular disease progression, such as mechanical stress, inflammatory mediators, hypertension, adhesion molecules, and thrombosis. The involvement of these components in vascular disease, as studied in animal and human in vitro and in vivo experiments, will be reviewed separately.

\section{Vascular NADPH oxidase produced ROS: animal in vitro studies \\ Phorbol-12-myristate-13-acetate (PMA)}

PMA, which is known to activate the NADPH oxidase in phagocytes, ${ }^{35}$ and NADPH administration resulted in increased ROS production in intact rat aortic segments, whereas only NADPH administration was able to enhance ROS production in mechanically denuded rat aortic endothelium. ${ }^{24}$ In porcine pulmonary artery endothelial cells, lucigenin chemiluminescence demonstrated increased ROS production upon PMA treatment, which was inhibited by the non-specific NADPH oxidase inhibitor diphenylene iodonium (DPI). ${ }^{14}$ In accordance with this observation, chemiluminescence showed that aortic endothelial segments of gp9lphox deficient mice exhibited an attenuated PMA induced NADPH dependent ROS production, whereas wild-type mice showed normal PMA induced increases in superoxide generation. ${ }^{24}$

In contrast, porcine coronary SMCs were shown to be inert to PMA stimulation, because superoxide values remained indifferent, in agreement with the lack of NADPH oxidase components in VSMCs. ${ }^{24}$

Mechanical stress

Flow adapted and shear stress exposed bovine pulmonary artery endothelial cells exhibited an increased ROS production compared with continuously perfused cells. This increase was inhibited by DPI, indicating that an NADPH oxidase may be activated by the shear stress. ${ }^{36}$

\section{Inflammatory mediators}

Cytokines have been shown to upregulate ROS production in vascular tissue. In particular, tumour necrosis factor $\alpha$ $(\mathrm{TNF}-\alpha)$ has been suggested to stimulate NADPH oxidase dependent superoxide production, because p22phox becomes 
upregulated upon TNF- $\alpha$ administration in cultured rat hypertensive aortic VSMCs. ${ }^{37}$ Interestingly, transfection with antisense p22phox nucleotides in rat aorta VSMCs abolished TNF- $\alpha$ induced superoxide production, implicating a p22phox based non-phagocyte NADPH oxidase as the source of ROS formation. ${ }^{37}$ Lipopolysaccharide (LPS) stimulates ROS production in rat aortic rings. ${ }^{38}$ This production could be inhibited by the non-specific NADPH oxidase inhibitor DPI. ${ }^{38}$ Furthermore, LPS induced an increase in the expression of p67phox and of an approximately $75 \mathrm{kDa}$ protein in rat aortic rings, as detected by western blotting with antibodies directed against the human p67phox and gp9lphox proteins, respectively. In contrast, northern blotting showed increased p22phox mRNA upon LPS administration. ${ }^{38}$

\section{Angiotensin II}

Angiotensin II (Ang II) plays an important role in the development of hypertension. It has been shown that upon Ang II administration superoxide values rise in rat aortic $\mathrm{SMCs}^{39} 40$ and throughout the rabbit aortic vascular wall (especially in endothelium and adventitia), ${ }^{41}$ and that this rise of superoxide values can be inhibited by DPI. It has been suggested that adventitial superoxide can inactivate endothelium derived nitric oxide, which enables the adventitia to play a role in the regulation of smooth muscle tone and in hypertension. ${ }^{19} 28{ }^{42}$ Results of several groups indicate that this Ang II induced superoxide production is mediated by an NADPH oxidase, ${ }^{19} 43$ among other mechanisms by upregulation of the mRNA expression of the NADPH oxidase component p67phox. ${ }^{29}$ In addition, transfection with antisense p22phox nucleotides in rat aortic SMCs inhibited Ang II induced superoxide generation. ${ }^{17}$

\section{Ischaemia}

Ischaemia of bovine pulmonary artery endothelial cells led to the generation of ROS and NF- $\mathrm{KB}$ and AP-1 induced DNA synthesis, as detected by means of electrophoretic mobility shift assays. Both effects were inhibited by the addition of DPI. $^{36}$

In summary, most of the studies mentioned above have used pharmacological inhibitors of ROS production to show NAPDH oxidase involvement. However, these compounds are not specific for NADPH oxidases, ${ }^{44}$ so definitive proof of NADPH oxidase mediated ROS production is still lacking. Nonetheless, transfection studies with antisense oligonucleotides specific for p22phox have shown a reduced superoxide production, implicating p22phox and, by extrapolation, an $\mathrm{NADPH}$ oxidase in ROS mediated processes in the vasculature. ${ }^{17}$

\section{Vascular NADPH oxidase produced ROS in human in vitro studies \\ PMA}

Apocynin, DPI, and other non-specific inhibitors attenuated ROS production in HUVEC cultures pretreated with PMA. ${ }^{44}$

\section{Mechanical stress}

Short term stretch increased superoxide generation in a DPI inhibitable manner in human aortic endothelial cells ${ }^{45}$ and in human coronary artery SMCs. ${ }^{46}$

\section{Inflammatory mediators}

In HUVECs, TNF- $\alpha$ stimulated ROS production, ${ }^{47}$ and DPI was shown to inhibit this reaction. ${ }^{48}$ The pro-atherosclerotic agent endothelin 1 upregulated gp9lphox mRNA expression and superoxide production in HUVECs. ${ }^{49}$

Platelet derived growth factor ${ }^{50}$ increased ROS production and, consecutively, upregulated various intracellular second messengers ${ }^{47} 48$ and intercellular adhesion molecules, such as vascular cell adhesion molecule 1 , in human endothelial cells. ${ }^{47} 48$ This upregulation was inhibited by DPI and apocynin. ${ }^{47} 4850$ In HUVECs, LPS and PMA induced E-selectin mRNA expression, as estimated by northern blot analysis, was inhibited by apocynin treatment, again suggesting a role of an NADPH oxidase in this process. ${ }^{51}$

Bradykinin was shown to induce the generation of ROS, phosphorylation of cytosolic mitogen activated protein kinases p42/p44, and c-fos mRNA expression in aortic VSMCs in a DPI and $N$-acetylcysteine inhibitable manner. ${ }^{52}$

\section{Angiotensin II}

Administering Ang II to human vascular endothelial cells resulted in a rise in superoxide concentration as detected by lucigenin enhanced chemiluminescence. ${ }^{53}$

\section{Coagulation factors}

The administration of thrombin, which is known to induce VSMC proliferation, and is therefore probably involved in atherogenesis, to human aortic SMCs, resulted in p47phox mRNA and protein upregulation and increased DPI inhibitable ROS production. ${ }^{29}$ In HUVECs, thrombin induced apocynin inhibitable ROS production. ${ }^{54}$ Exposure of aortic SMCs and mesenteric SMCs to products released from activated human platelets resulted in enhanced p22phox expression and intracellular ROS production, in addition to upregulation of tissue factor mRNA expression in a DPI inhibitable manner. ${ }^{16}$ Tissue factor is a major activator of the coagulation cascade leading to the generation of thrombin.

In summary, there is an increasing amount of evidence, circumstantial at the moment, for an important role of NADPH oxidase(s) in the human vasculature.

\section{Vascular NADPH oxidase produced ROS: animal in vivo studies}

Although in vivo experiments have been performed on a very limited scale so far, this experimental approach is of vital importance in investigating the influence of NADPH oxidase dependent ROS production on vascular disease. RT-PCR indicated increased p22phox mRNA expression in aortic medial VSMCs, ${ }^{55}$ in addition to adventitial smooth muscle tissue $^{56}$ of hypertensive rats. In wild-type and gp9lphox knockout mice, no differences in plasma lipid values and atherosclerotic lesion size were found after a high fat diet of 20 weeks. The authors concluded that the phagocyte NADPH oxidase does not contribute greatly to the aetiology of atherosclerosis. ${ }^{57}$ Immunohistochemistry in male Sprague Dawley rats demonstrated increased p47phox expression throughout the rat aortic vascular wall following catheter induced injury, whereas uninjured arteries showed only adventitial and low level medial VSMC p47phox expression. ${ }^{29}$ However, in p47phox knockout mice, no differences were found in atherosclerotic lesion size and basal blood pressure compared with a p47phox positive control group, although vascular superoxide generation was decreased by $50 \%$ in aortic rings from the knockout mice. ${ }^{58}$

Clearly, this experimental approach is just beginning to unravel the functional contribution of gp9lphox and its homologues to vascular pathophysiology.

\section{Vascular NADPH oxidase produced ROS: human in vivo studies}

Studies on the role of ROS produced by the vascular NADPH oxidase(s) in humans are restricted to mutational analysis or polymorphism studies; that is, the analysis of the effects of mutations or polymorphisms in one of the oxidase components on the phenotype of the affected individuals. So far, only patients with CGD (individuals with defects in one of the phagocyte NADPH oxidase components) have been the subject of mutational analysis. No vascular deficiencies have been described in these patients. 
In recent years, several studies have investigated the possible effects of polymorphisms of p22phox on the vasculature. Four different polymorphisms have so far been reported, ${ }^{59}$ and two of these, C242T and A640G, have been analysed as to their role in atherogenesis.

\begin{abstract}
"Studies on the role of reactive oxygen species produced by the vascular NADPH oxidase(s) in humans are restricted to mutational analysis or polymorphism studies"
\end{abstract}

The C242T polymorphism results in a His72 $\rightarrow$ Tyr substitution in the p22phox protein. Cahilly et al found that the homozygous $\mathrm{T}$ genotype and the TC genotype of the C242T polymorphism of p22phox are associated with a greater loss in mean minimum lumen diameter, increased progression of coronary artery disease (CAD), and less regression of the disease under treatment as assessed by coronary angiography than the homozygous $C$ genotype.$^{60}$ Cai et al showed in a white Australian population that the TC and TT genotypes of the C242T polymorphism were more abundant in young male patients with CAD ( $\leqslant 45$ years old), whereas an association of the C242T polymorphism with CAD could not be established in the total patient population. ${ }^{61}$ In contrast to these results, Inoue et al showed that in a Japanese population, the TC + TT genotypes of the C242T polymorphism were found significantly more frequent in control subjects than in patients with $\mathrm{CAD}^{62}$ and a study of an American population of 252 patients undergoing angiography for the diagnosis of CAD found no significant difference in the prevalence of the C242T allele between controls and patients with $\mathrm{CAD}^{6{ }^{63}} \mathrm{~A}$ combined biracial study of Asian Indians and Chinese from Singapore did not reveal an increased allelic prevalence in either the control group or the patients with CAD. ${ }^{64}$ However, a study of 2205 male white Europeans, although not detecting an association of the C242T polymorphism with CAD, found a clear association of the A640G polymorphism with CAD, the AA genotype being found preferentially in patients with CAD.$^{65}$ This is again in contrast to the findings of Inoue et al in a Japanese population, which showed an equal allele distribution of the A640G polymorphism among controls and patients with CAD. ${ }^{62}$ In another study, patients with cerebrovascular disease were shown to express the TC and TT genotypes of the C242T polymorphism more frequently than controls, suggesting that p22phox polymorphism possibly constitutes a risk factor for cerebrovascular disease. ${ }^{66}$

\section{DISCUSSION}

Although there can be no doubt about the important contribution of ROS to a variety of (patho)physiological vascular processes such as atherosclerosis, the source, regulation, and precise functional relevance of vascular ROS production still remain to be clearly defined. Many findings point in the direction of one or more NADPH oxidase(s) central to ROS producing system(s), but despite the recent emergence of non-phagocytic gp9lphox homologues definitive proof of this assumption is still lacking. In vitro inhibition studies of ROS production have established the role of ROS in the upregulation of adhesion molecules, ${ }^{6768}$ activation of transcription factors, ${ }^{69}{ }^{70}$ hypertrophy, ${ }^{40} 71$ cell proliferation, ${ }^{17}$ migration, ${ }^{1}$ and ultimately atherosclerosis. ${ }^{28}{ }^{42}$ However, the reliance of these experiments on pharmacological non-specific inhibitors and scavengers, such as DPI and $N$-acetylcysteine, has limited the conclusions to be drawn from this research.

A very suggestive, yet circumstantial, piece of evidence implicating an NADPH oxidase system comparable to that found in phagocytes in the generation of ROS in the vasculature is the demonstration of almost all phagocyte NADPH oxidase components throughout all layers of the vascular wall. It

\section{Take home messages}

- Almost all phagocyte NADPH oxidase components are found throughout all layers of the vascular wall

- In non-phagocytes, reactive oxygen species have a role in a variety of essential intracellular and intercellular signal transduction pathways and are active at much lower physiological concentrations

- The source, regulation, and precise functional relevance of vascular reactive oxygen species still remain to be clarified

will be very interesting to learn which gp9lphox homologues serve as catalytic centres in these systems and the exact functional relevance of the presence or absence of the other oxidase subunits in the different vascular tissues. Indeed, in phagocytic cells the cytosolic components function in the regulation of a very intense, burst-like generation of ROS corresponding to the need for killing pathogens. In contrast, in non-phagocytic cells, ROS have a role in a variety of essential intracellular and, possibly, intercellular signal transduction pathways, such as cell differentiation and proliferation, apoptosis, and oxygen sensing, and are therefore active at much lower physiological concentrations. The amounts of superoxide produced by the Noxl based oxidase system, for instance, are much lower than those produced by phagocytic oxidase. ${ }^{30}$ How then, is the regulatory machinery of the oxidase(s) adapted to this difference in function and, probably, subcellular localisation? Which are the target molecules modified by the generated ROS and what are the consequences of the dysregulation of these systems under pathological conditions? The elucidation of these and other questions will benefit enormously from the rapidly progressing characterisation at the molecular level of the enzyme systems involved.

"In non-phagocytic cells, reactive oxygen species have a role in a variety of essential intracellular and, possibly, intercellular signal transduction pathways and are therefore active at much lower physiological concentrations"

This characterisation will also permit the establishment of mouse models for the further elucidation of the role ROS based signalling plays in vascular health and disease and the genotypic and phenotypic characterisation of affected human individuals, thereby opening new diagnostic and, possibly, therapeutic options for such vascular disease states as hypertension and atherosclerosis.

\section{ACKNOWLEDGEMENT}

Dr Niessen is a recipient of the Dr E Dekker programme of the Netherlands Heart Foundation (D99025).

\section{Authors' affiliations}

C J L M Meijer, H W M Niessen, Department of Pathology, Free University Medical Center, PO Box 7057, 1007 MB Amsterdam, 1006 AD Amsterdam, The Netherlands

C Meischl, D Roos, Central Laboratory of the Netherlands Blood Transfusion Service (CLB) and Laboratory for Experimental and Clinical Immunology, Academic Medical Center, University of Amsterdam, The Netherlands

W Stooker, Department of Cardiac Surgery, Free University Medical Center,

L Van Heerebeek, Institute of Cardiovascular Research, Free University Medical Center

The first two authors contributed equally to the preparation of this paper.

\section{REFERENCES}

1 Griendling KK, Sorescu D, Ushio-Fukai M. NAD(P)H oxidase: role in cardiovascular biology and disease. Circ Res 2000;86:494-501. 
2 Seifert $\mathbf{R}$, Schultz G. Superoxide forming NADPH oxidase of phagocytes: an enzyme system regulated by multiple mechanisms. Rev Physiol Biochem Pharmacol 1991;117:1-338.

3 Roos D, de Boer M, Kuribayashi F, et al. Mutations in the X-linked and autosomal recessive forms of chronic granulomatous disease. Blood 1996:87:1663-81.

4 Thelen M, Dewald B, Baggiolini M. Neutrophil signal transduction and activation of the respiratory burst. Physiol Rev 1994;73:797-82 1

5 Leusen JH, de Klein A, Hilarius PM, et al. Disturbed interaction of p2 1-rac with mutated p67phox causes chronic granulomatous disease. $J$ Exp Med 1996;184:1243-9.

6 Sumimoto $M$, Kage $Y$, Nunoi $H$, et al. Role of Src homology 3 domains in assembly and activation of the phagocyte NADPH oxidase. Proc Natl Acad Sci U S A 1994;91:5345-9.

7 Heywoth PG, Bohl BP, Bokoch GM, et al. Rac translocates independently of the neutrophil NADPH oxidase components p47phox and p67phox. Evidence for its interaction with flavocytochrome b558. J Biol Chem 1994;269:30749-52.

8 Thrasher AJ, Keep NH, Wientjes F, et al. Chronic granulomatous disease. Biochim Biophys Acta 1994;1 227:1-24.

9 Meier B, Jesaitis AJ, Emmendörffer A, et al. The cytochrome $b_{558}$ molecules involved in the fibroblast and polymorphonuclear leucocyte superoxide-generating NADPH oxidase systems are structurally and genetically distinct. Biochem J 1993;289:481-6.

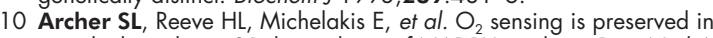
mice lacking the gp9 1 phox subunit of NADPH oxidase. Proc Natl Acad Sci U S A 1999:96:7944-9.

11 Kaneda M, Sakuraba H, Ohtake A, et al. Missense mutations in the gp9 1 phox gene encoding cytochrome $b_{558}$ in patients with cytochrome $b$ positive and negative X-linked chronic granulomatous disease. Blood 1999; 93:2098-104

12 Bayraktutan U, Blayney L, Shah AM. Molecular characterization and localization of the NAD(P)H oxidase components gp9 1 phox and p22phox in endothelial cells. Arterioscler Thromb Vasc Biol 2000;20:1903-1 1.

13 Bayraktutan U, Draper N, Lang D. et al. Expression of functional neutrophil-type NADPH oxidase in cultured rat coronary microvascular endothelial cells. Cardiovasc Res 1998:38:256-62.

14 Höhler B, Holzapfel B, Kummer W. NADPH oxidase subunits and superoxide production in porcine pulmonary artery endothelial cells. Histochem Cell Biol 2000; 1 14:29-37.

15 Fukui $T$, Lassegue $B$, Kai $H$, et al. Cytochrome $b_{558}$ alpha subunit cloning and expression in rat aortic smooth muscle cells. Biochim Biophys Acta 1995:1231:215-19.

16 Görlach A, Brandes R, Bassus $S$, et al. Oxidative stress and expression of $\mathrm{p} 2 \mathrm{phox}$ are involved in the up-regulation of tissue factor in vascular smooth muscle cells in response to activated platelets. FASEB J 2000;14:1518-28.

17 Ushio-Fukai M, Zafari AM, Fukui T, et al p22phox is a critical component of the superoxide-generating NADH/NADPH oxidase system and regulates angiotensin II induced hypertrophy in vascular smooth muscle cells. J Biol Chem 1996;271:23317-21

18 Di Wang H, Pagano PJ, Du Y, et al. Superoxide anion from the adventitia of the rat thoracic aorta inactivates nitric oxide. Circ Res 1998;82:810-18.

19 Pagano PJ, Clark JK, Cifuentes-Pagano ME, et al. Localization of a constitutively active, phagocyte like NADPH oxidase in rabbit aortic adventitia: enhancement by angiotensin II. Proc Natl Acad Sci U S A 1997:94:14483-38

20 Marshall C, Mamary AJ, Verhoeven AJ, et al. Pulmonary artery NADPH oxidase is activated in hypoxic pulmonary vasoconstriction. Am J Respir Cell Mol Biol 1996; 15:633-44

21 Al-Mehdi AB, Zhao G, Dodia C, et al. Endothelial NADPH oxidase as the source of oxidants in lungs exposed to ischemia or high $\mathrm{K}+$. Circ Res 1998:83:730-7.

22 Pagano PJ, Chanock SJ, Siwik DA, et al. Angiotensin II induces p67phox mRNA expression and NADPH oxidase superoxide generation in rabbit aortic adventitial fibroblasts. Hypertension 1998;32:331-7.

23 Jones SA, O'Donnell VB, Wood JD, et al. Components in human endothelial cells. Am J Physiol 1996;271:H1626-34.

24 Görlach A, Brandes RP, Nguyen K, et al. A gp9 l phox containing NADPH oxidase selectively expressed in endothelial cells is a major source of oxygen radical generation in the arterial wall. Circ Res 2000;87:26-32

25 Meyer JW, Holland JA, Ziegler LM, et al. Identification of a functional leukocyte type NADPH oxidase in human endothelial cells: a potentia atherogenic source of reactive oxygen species. Endothelium 1999;7: 1 1-22.

26 Azumi H, Inoue N, Takeshita S, et al. Expression of NADH/NADPH oxidase p22phox in human coronary arteries. Circulation 1999:100:1494-8.

27 Lynn S, Gurr JR, Lai HT, et al. NADH oxidase activation is involved in arsenite-induced oxidative DNA damage in human vascular smooth muscle cells. Circ Res 2000;86:514-19.

28 Yokoyama M, Inove N, Kawashima S. Role of the vascular $\mathrm{NADH} / \mathrm{NADPH}$ oxidase system in atherosclerosis. Ann N Y Acad Sci 2000;902:241-7.

29 Patterson C, Ruef J, Madamanchi NR, et al. Stimulation of a vascular smooth muscle cell $\mathrm{NAD}(\mathrm{P}) \mathrm{H}$ oxidase by thrombin: evidence that p47phox may participate in forming this oxidase in vitro and in vivo. Biol Chem 1999:274:19814-22.

30 Suh YA, Arnold RS, Lassegue B, et al. Cell transformation by the superoxide generating oxidase Mox1. Nature 1999;401:79-82.
31 Kikuchi $\mathbf{H}$, Hikage M, Miyashita $\mathrm{H}$, et al. NADPH oxidase subunit, gp9 1 phox homologue, preferentially expressed in human colon epithelial cells. Gene 2000;254:237-43

32 Geiszt M, Kopp JB, Varnai P, et al. Identification of Renox, an NAPDH oxidase in kidney. Proc Natl Acad Sci U S A 2000;97:8010-14.

33 Shiose A, Kuroda J, Tsuruya K, et al. A novel superoxide-producing NAD(P)H oxidase in kidney. J Biol Chem 2001;276:1417-23.

34 De Deken X, Wang D, Many MC, et al. Cloning of two human thyroid cDNAs encoding new members of the NADPH oxidase family. J Biol Chem 2000;275:23227-33.

35 Repine JE, White JG, Clawson GG, et al. The influence of phorbol myristate acetate on oxygen consumption of peripheral blood leukocytes. J Lab Clin Med 1974;83:911-20.

36 Wei Z, Costa K, Al-Mehdi AB, et al. Simulated ischemia in flow-adapted endothelial cells leads to generation of reactive oxygen species and cell signalling. Circ Res 1999;85:682-9.

37 De Keulenaer GW, Alexander RW, Ushio-Fukai M, et al. Tumour necrosis factor alpha activates a p22phox based NADH oxidase in vascular smooth muscle. Biochem J 1998;329:653-7.

38 Brandes RP, Koddenberg G, Gwinner W, et al. Role of increased production of superoxide anions by $\mathrm{NAD}(\mathrm{P}) \mathrm{H}$ oxidase and xanthine oxidase in prolonged endotoxemia. Hypertension 1999;33:1243-9.

39 Viedt C, Soto U, Krieger-Braver HI, et al. Differential activation of mitogen-activated protein kinases in smooth muscle cells by angiotensin II: involvement of p22phox and reactive oxygen species. Arterioscler Thromb Vasc Biol 2000;20:940-8.

40 Zafari AM, Ushio-Fukai $M$, Akers $M$, et al. Role of NADH/NADPH oxidase-derived $\mathrm{H}_{2} \mathrm{O}_{2}$ in angiotensin II induced vascular hypertrophy. Hypertension 1998;32:488-95.

41 Nakane H, Miller FJ, Jr, Faraci FM, et al. Gene transfer of endothelial nitric oxide synthase reduces angiotensin II-induced endothelial dysfunction. Hypertension 2000;35:595-601

42 Di Wang H, Hope S, Du Y, et al. Paracrine role of adventitial superoxide anion in mediating spontaneous tone of the isolated rat aorta in angiotensin Il-induced hypertension. Hypertension 1999;33:1225-32.

43 Griendling KK, Minieri CA, Ollerenshaw JD, et al. Angiotensin II stimulates NADH and NADPH oxidase activity in cultured vascular smooth muscle cells. Circ Res 1994;74:1141-8.

44 Holland J, O'Donnell R, Chang M, et al. Endothelial cell oxidant production: effect of NADPH oxidase inhibitors. Endothelium 2000; 7: 109-19

45 Hishikawa K, Luscher TF. Pulsatile stretch stimulates superoxide production in human aortic endothelial cells. Circulation 1997:96:3610-16.

46 Hishikawa K, Oemar BS, Yang Z, et al. Pulsatile stretch stimulates superoxide production and activates nuclear factor-kappa $B$ in human coronary smooth muscle. Circ Res 1997;81:797-803.

47 Weber C, Erl W, Pietsch A, et al. Antioxidants inhibit monocyte adhesion by suppressing nuclear factor kappa B mobilization and induction of vascular cell adhesion molecule 1 in endothelial cells stimulated to generate radicals. Arterioscler Thromb 1994;14:1665-73.

48 Bhunia AK, Arai T, Bulkley G, et al. Lactosylceramide mediates tumor necrosis factor alpha induced intercellular adhesion molecule 1 (ICAM-1) expression and the adhesion of neutrophils in human umbilical vein endothelial cells. J Biol Chem 1998;273:34349-57.

49 Duerrschmidt N, Wippich N, Goettsch W, et al. Endothelin-1 induces $\mathrm{NAD}(\mathrm{P}) \mathrm{H}$ oxidase in human endothelial cells. Biochem Biophys Res Commun 2000;269:713-17.

50 Marumo T, Schini-Kerth VB, Fisslthaler B, et al. Platelet-derived growth factor-stimulated superoxide anion production modulates activation of transcription factor NF-kappaB and expression of monocyte chemoattractant protein 1 in human aortic smooth muscle cells. Circulation 1997; 96:2361-7.

51 Suzuki Y, Wang W, Vu TH, et al. Effect of NADPH oxidase inhibition on endothelial cell ELAM-1 mRNA expression. Biochem Biophys Res Commun 1992;184:1339-43.

52 Greene EL, Velarde V, Jaffa AA. Role of reactive oxygen species in bradykinin-induced mitogen activated protein kinase and c-fos induction in vascular cells. Hypertension 2000;35:942-7.

53 Zhang H, Schmeisser A, Garlichs CD, et al. Angiotensin II induced superoxide anion generation in human vascular endothelial cells: role of membrane bound NADH/NADPH oxidases. Cardiovasc Res 1999;44:215-22

54 Holland JA, Meyer JW, Chang MM, et al. Thrombin stimulated reactive oxygen species production in cultured human endothelial cells. Endothelium 1998:6:113-21.

55 Zalba G, Beaumont FJ, San Jose G, et al. Vascular NADH/NADPH oxidase is involved in enhanced superoxide production in spontaneously hypertensive rats. Hypertension 2000;35:1055-61.

56 Fukui T, Ishizaka N, Rajagopalan S, et al. p22phox mRNA expression and NADPH oxidase activity are increased in aortas from hypertensive rats. Circ Res 1997;80:45-51.

57 Kirk EA, Dinauer MC, Rosen H, et al. Impaired superoxide production due to a deficiency in phagocyte NADPH oxidase fails to inhibit atherosclerosis in mice. Arterioscler Thromb Vasc Biol 2000;20:152935.

58 Hsich E, Segal BH, Pagano PJ, et al. Vascular effect following homozygous disruption of p47phox: an essential component of NADPH oxidase. Circulation 2000;101:1234-6.

59 de Boer $M$, de Klein A, Hossle J-P, et al. Cytochrome $b_{558}$-negative, autosomal recessive chronic granulomatous disease: two new mutations in the cytochrome $b_{558}$ light chain of the NADPH oxidase (p22phox). Am J Hum Genet 1992;51:1127-35. 
60 Cahilly C, Ballantyne CM, Lim DS, et al. A variant of p22phox, involved in generation of reactive oxygen species in the vessel wall, is associated with progression of coronary atherosclerosis. Circ Res 2000;86:391-5.

61 Cai H, Duarte N, Wilcken DEL, et al. NADH/NADPH oxidase p22phox $\mathrm{C}^{242} \mathrm{~T}$ polymorphism and coronary artery disease in the Australian population. Eur J Clin Invest 1999;29:744-8.

62 Inoue N, Kawashima S, Kanazawa K, et al. Polymorphism of the NADH/NADPH oxidase p22phox gene in patients with coronary artery disease. Circulation 1998;97:135-7.

63 Li A, Prasad A, Mincemoyer R, et al. Relationship of the C ${ }^{242} \mathrm{~T}$ p22phox gene polymorphism to angiographic coronary artery disease and endothelial function. Am J Med Genet 1999;86:57-61.

64 Saha N, Sanghera DK, Kamboh MI. The p22phox polymorphism C242T is not associated with CHD risk in Asian Indians and Chinese. Eur J Clin Invest 1999;29:999-1002.

65 Gardemann A, Mages P, Katz N, et al. The p22phox A640G gene polymorphism but not the $\mathrm{C} 242 \mathrm{~T}$ gene variation is associated with coronary heart disease in younger individuals. Atherosclerosis $1999 ; 145: 315-23$
66 Ito D, Murata M, Watanabe K et al. $C^{242}$ T polymorphism of NADPH oxidase $\mathrm{p} 22$ phox gene and ischemic cerebrovascular disease in the Japanese population. Stroke 2000;31:936-9.

67 Chatteriee S. Sphingolipids in atherosclerosis and vascular biology. Arterioscler Thromb Vasc Biol 1998;18:1523-33.

68 Arai T, Bhunia AK, Chatterjee $S$, et al. Lactosylceramide stimulates human neutrophils to upregulate Mac-1, adhere to endothelium, and generate reactive oxygen metabolites in vitro. Circ Res 1998;82:540-7.

69 Fei J, Viedt C, Soto U, et al. Endothelin-1 and smooth muscle cells: induction of Jun amino terminal kinase through an oxygen radical sensitive mechanism. Arterioscler Thromb Vasc Biol 2000;20:1244-9.

70 Bhunia AK, Han H, Snowden A, et al. Redox-regulated signaling by actosylceramide in the proliferation of human aortic smooth muscle cells. J Biol Chem 1997;272:15642-9

71 Lang D, Mosfer SO, Shakesby A, et al. Coronary microvascular endothelial cell redox state in left ventricular hypertrophy: the role of angiotensin II. Circ Res 2000;86:463-9.

\section{Call for peer reviewers}

Clinical Evidence is a regularly updated evidence based journal available world wide both as a paper version and on the internet. Clinical Evidence urgently needs to recruit a number of new contributors. Contributors are health care professionals or epidemiologists with experience in evidence based medicine and the ability to write in a concise and structured way.

Clinical Evidence needs to recruit a number of new peer reviewers. Peer reviewers are health care professionals or epidemiologists with experience in evidence based medicine. As a peer reviewer you would be asked for your views on the clinical relevance, validity and accessibility of specific topics within the journal, and their usefulness to the intended audience (international generalists and health care professionals, possibly with limited statistical knowledge). Topics are usually 2000-3000 words in length and we would ask you to review between 2-5 topics per year. The peer review process takes place throughout the year, and our turnaround time for each review is ideally 10-14 days.

If you are interested in becoming a peer reviewer for Clinical Evidence, please complete the peer review questionnaire at www.clinicalevidence.com or contact Polly Brown (pbrown@bmigroup.com). 